\title{
Prevalence of High-Riding Vertebral Artery and Morphometry of C2 Pedicles Using a Novel Computed Tomography Reconstruction Technique
}

\author{
Wiwat Wajanavisit ${ }^{1}$, Thamrong Lertudomphonwanit ${ }^{1}$, Praman Fuangfa ${ }^{2}$, \\ Pongsthorn Chanplakorn ${ }^{1}$, Chaiwat Kraiwattanapong ${ }^{1}$, Supaneewan Jaovisidha ${ }^{2}$ \\ ${ }^{1}$ Department of Orthopedics, Faculty of Medicine, Ramathibodi Hospital, Mahidol University, Bangkok, Thailand \\ ${ }^{2}$ Department of Radiology, Faculty of Medicine, Ramathibodi Hospital, Mahidol University, Bangkok, Thailand
}

Study Design: Cross-sectional, matched-pair comparative study.

Purpose: To determine whether a thin-sliced pedicular-oriented computed tomography (TPCT) scan reconstructed from an existing conventional computed tomography (CCT) scan is more accurate for identifying vertebral artery groove (VAG) anomalies than CCT.

Overview of Literature: Posterior atlantoaxial transarticular screw fixation and C2 pedicle screws can cause vertebral artery (VA) injury. Two anatomic variations of VAG anomalies are associated with VA injury: a high-riding VA (HRVA) and a narrow pedicle of the C2 vertebra. CCT scan is a reliable method used to evaluate VAG anomalies; however, its accuracy level remains debatable. Literature comparing the prevalence of C2 VAG anomalies between CCT and TPCT is limited.

Methods: A total of 200 computed tomography scans of the upper cervical spine obtained between January 2008 and December 2011 were evaluated for C2 VAG anomalies (HRVA and narrow pedicular width) using CCT and TPCT. The prevalence of C2 VAG anomalies was compared using these two different measurement methods via a McNemar's test.

Results: Of the 200 patients studied, 23 HRVA (6.01\%; 95\% confidence interval [CI], 3.61\%-8.39\%) were detected with CCT, whereas 66 HRVA (16.54\%; $95 \% \mathrm{Cl}, 12.85 \%-20.23 \%)$ were detected with TPCT ( $p<0.001)$. Sixty-two narrow pedicles (15.58\%; $95 \% \mathrm{Cl}$, $11.99 \%-19.15 \%)$ were detected with CCT, whereas 90 narrow pedicles $(22.83 \% ; 95 \%$ Cl, $18.58 \%-26.87 \%)$ were detected with TPCT $(p<0.001)$.

Conclusions: VAG anomalies are commonly observed. A preoperative evaluation using TPCT reconstructed from an existing CCT revealed a significantly higher prevalence of C2 VAG anomalies than did CCT and showed comparable prevalence to previously published studies using more sophisticated and higher risk techniques. Therefore, we propose TPCT as an alternative preoperative evaluation for $\mathrm{C} 2$ screw placement and trajectory planning.

Keywords: Vertebral artery; High-riding vertebral artery; Pedicle; X-ray computed tomography; C2 screw

\section{Introduction}

Posterior atlantoaxial transarticular screw fixation and segmental screw fixation of the C1 lateral mass and C2 pedicle are acceptable methods used to stabilize the atlantoaxial joint [1]. Previous studies demonstrate that both

\footnotetext{
Received Mar 18, 2016; Revised Apr 23, 2016; Accepted May 8, 2016

Corresponding author: Thamrong Lertudomphonwanit

Department of Orthopedics, Faculty of Medicine, Ramathibodi Hospital, Mahidol University,

270 Rama VI Road, Ratchathewi, Bangkok, 10400, Thailand

Tel: +66-2-2011589, Fax: +66-2-6520306, E-mail: thamrong.lert@gmail.com
} 
screw fixation techniques can result in vertebral artery (VA) injury with potentially catastrophic complications [2-4]. Compared with transarticular screw placement, the more superior and medial trajectory of $\mathrm{C} 2$ pedicular screws decreases the risk of VA injury [5]; however, recent studies have reported that the anatomical risk of VA injury does not significantly differ between these two techniques $[6,7]$.

The reported rate of VA injury ranged from $4.1 \%$ to $8.2 \%$ for posterior atlantoaxial transarticular screw fixation $[3,4]$, whereas the prevalence of VA injury with the C2 pedicular screw was $5.3 \%-21 \%[8,9]$. Several factors contribute to VA injury, including a VA groove (VAG) anomaly or surgical technique involving the insertion of the screw extremely close to the VA $[2,3,10,11]$. Therefore, several authors recommend that VAG anomalies should be preoperatively evaluated using a computed tomography (CT) scan [12-14]. Identifying the variation of VA and determining the screw fixation method will be helpful to avoid unnecessary damage during upper cervical spinal surgery [12].

Considering the anatomic course of the VA, there are two anatomic variations associated with VA injury: (1) a high-riding VA (HRVA) that increases the risk of VA injury during $\mathrm{C} 1-2$ transarticular screw fixation $[3,10,11,15]$; and (2) a narrow C2 pedicle that increases the risk of VA injury by a C2 pedicular screw. The prevalence of HRVA and a narrow C2 pedicle has been reported to be $14.5 \%-18 \%$ and $9.5 \%-32 \%$, respectively $[7,12,13]$. Jun [16] examined sagittal reconstructed CT images at 3.5 and 6 $\mathrm{mm}$ from the lateral border of the spinal canal. Their findings indicated that the safest screw trajectory is through the most posterior and medial portion of the narrow isthmus. Wang et al. [12] used a CT scan with a C2 pedicularoriented plane to obtain consecutive pictures of the VAG of $\mathrm{C} 2$ and evaluated the HRVA and pedicular width. Their findings suggest that the VAG of C2 analyzed by a thinslice CT scan with a pedicular-oriented plane can be used to assess an individual screw placement method. In addition, previous studies have reported the prevalence of HRVA and a narrow $\mathrm{C} 2$ pedicle using three-dimension CT angiography (3D-CTA), which is a highly sophisticated method and required an injection of contrast medium $[17,18]$. Therefore, the patients were exposed to the risk of iodinated contrast media. Other studies have utilized cadavers to determine the prevalence of HRVA and a narrow $\mathrm{C} 2$ pedicle $[3,11]$.
Although a conventional CT (CCT) scan is considered to be a reliable method to evaluate VAG anomalies, it remains debatable whether it is the most accurate technique. The reliability of the CT scan data depends on the proper scanning technique and image interpreter. Despite adequate reader training, clinically significant error persists [19]. Kim et al. [19] found that a 1.0- and 2.5-mm slice thickness in an axial CT scan was superior to that obtained with a 5.0-mm axial slice thickness for assessing cervical pedicular screw placement. Due to the difficulty in identifying VAG anomalies using CCT scans, we conducted this study to evaluate whether the thin-sliced axial and sagittal reformation in the pedicular-oriented plane is more accurate to identify a VAG anomaly. Moreover, we aimed to describe a simple and safe method for identifying VAG anomalies.

\section{Materials and Methods}

This study was approved by our Institutional Review Board. CT scans (Somatom Sensation 64 slides; SIEMENS, Berlin, Germany) of the cervical spine of all patients were obtained at our institution between January 2008 and December 2011, and were initially included in our study. The CT scans of patients aged younger than 20 years; patients with trauma, tumors, or infections of the upper cervical spine; prior upper cervical spine surgery or the presence of a congenital anomaly; as well as scans revealing metallic artifacts were excluded from the study.

For CCT scan measurements, routine axial and sagittal reformation was used. The axial slice (1-mm-thick) was along the orthogonal horizontal plane. The pedicular width of the $\mathrm{C} 2$ was measured on the VAG in the entrance slice of the CT scan. The sagittal slice (3-mm-thick) was along the plane vertical to the coronal plane of the body. The measurement was performed by a musculoskeletal radiologist (P.F.) who was unaware of the inclusion criteria for this study to eliminate potential measurement bias. The authors selected the slice that was the most medial to the lateral border of the spinal canal $(3 \mathrm{~mm}$ from the lateral border of the spinal canal). The isthmus height of $\mathrm{C} 2$ and internal height of the lateral mass (from the roof of the VAG to the surface of the superior facet) were measured.

For the thinly-sliced pedicular-oriented CT (TPCT) scan measurement, all the CCT scans were converted into TPCT scans (Fig. 1). The plane along the long axis of 


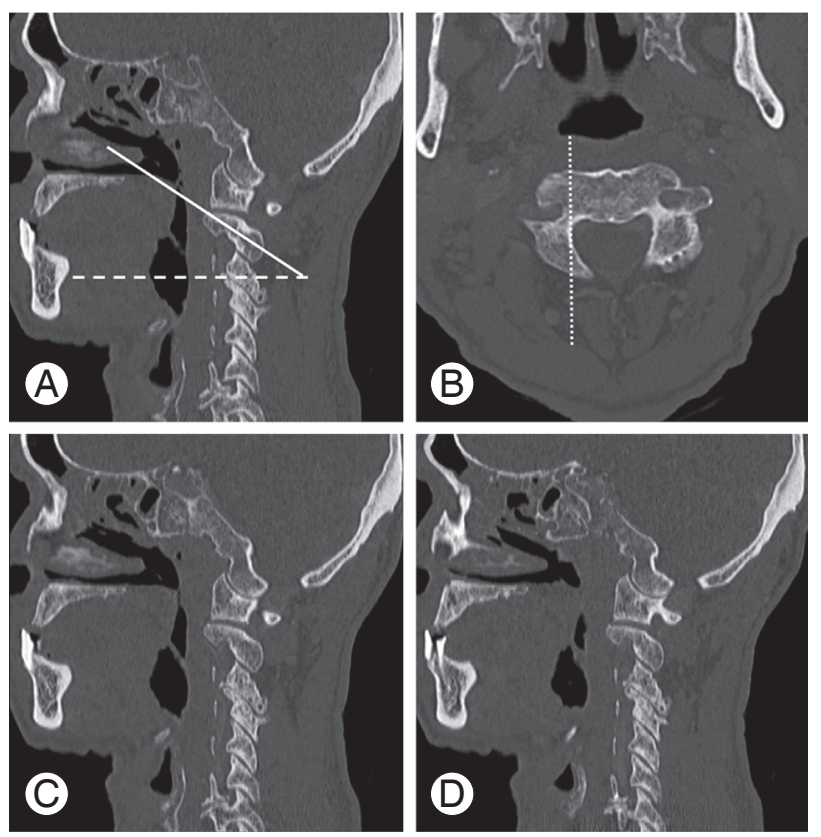

Fig. 1. A thin-sliced pedicular-oriented computed tomography scan is reformatted from the conventional sagittal plane (A). The dashed line in panel $(\mathbf{A})$ is parallel to the horizontal plane. The angle between the solid line and dashed line in panel (A) is approximately $20^{\circ}$. The axial pedicular-oriented plane $(\mathbf{B})$ is parallel to the solid line in panel $(\mathbf{A})$. The dotted line in panel $(\mathbf{B})$ is at the level of the lateral border of the spinal canal. The isthmus height of the $\mathrm{C} 2$ pedicle and internal height of the lateral mass are measured from a new sagittal plane at $2 \mathrm{~mm}$ (C) and $3 \mathrm{~mm}$ (D) right and lateral to the dotted line in panel (B).

the pedicle with a 1-mm slice thickness was reformatted. The C2 pedicular width was measured on the VAG for the entrance slice of the CT scan. The sagittal slices were reformatted to $1 \mathrm{~mm}$ thickness and measured at 2 and 3 $\mathrm{mm}$ from the lateral border of the spinal canal. These distances were used in consideration of the frequently used 3.5-mm diameter screw and according to the screw entry point from the previous study by Paramore et al. [13]. The isthmus height of $\mathrm{C} 2$ was measured perpendicular to the screw trajectory [15], and the internal height of the lateral mass was also measured.

The prevalence of a VAG anomaly of C2 between the two different measurement methods was subsequently measured for all patients included in the study. The VAG anomaly was divided into two groups. The first group had a HRVA defined as having an isthmus height of $\leq 5 \mathrm{~mm}$ and/or an internal height of $\leq 2 \mathrm{~mm}$ on the sagittal image 2-3 mm lateral to the cortical border of the spinal canal at C2. This definition was adapted from previous studies by Yeom et al. [7], Neo et al. [10], and Bloch et al. [15]. The second group exhibited a narrow $\mathrm{C} 2$ pedicle, which was defined as having the largest pedicular width of $\leq 4 \mathrm{~mm}$ on the axial image, as the diameter of commonly used screws is 3.5 or $4.0 \mathrm{~mm}$. [7]. The statistical analysis was performed using McNemar's test. The level of significance was set at $p<0.05$.

\section{Results}

A total of 200 patients were included in our study. The mean age was $57.2 \pm 16.3$ years (range, $20-90$ years). There were 109 male patients (54.5\%) and 91 (45.5\%) females. From the original diagnoses, there were 79 patients (39.5\%) with thyroid and parathyroid diseases, 28 patients (14\%) with cervical spine diseases, 24 patients (12\%) with oropharyngeal diseases, 21 patients $(10.5 \%)$ with nasopharyngeal diseases, and 48 patients (24\%) with other diseases (e.g., dental, larynx, facial bone, and sinus diseases) in the head and neck regions (Table 1).

According to the CCT, the mean width of the $\mathrm{C} 2$ pedicle was $5.07 \mathrm{~mm}$ (range, 1.1-9.31 mm; standard deviation [SD], 1.31), the mean internal height was $5.61 \mathrm{~mm}$ (range, 1.17-15.24 mm; SD, 2.3), and the mean isthmus height was $10.18 \mathrm{~mm}$ (range, 4.44-20.02 mm; SD, 1.85) (Table 2).

From the TPCT, the mean width of the $\mathrm{C} 2$ pedicle was $4.87 \mathrm{~mm}$ (range, 1.1-9.11 mm; SD, 1.27), the mean internal height at 2-mm sagittal section was $5.27 \mathrm{~mm}$ (range, 1.17-12.1 mm; SD, 1.61), the mean internal height at 3-mm sagittal section was $4.51 \mathrm{~mm}$ (range, $0.87-11.59$ $\mathrm{mm}$; SD, 2.16), the mean isthmus height at 2-mm sagittal section was $10.28 \mathrm{~mm}$ (range, $5.42-15.31 \mathrm{~mm}$; SD, 1.61), and the mean isthmus height at $3-\mathrm{mm}$ sagittal section was

Table 1. Demographic data

\begin{tabular}{lc} 
Demographic data & No. $(\%)$ \\
Sex & \\
Male & $109(54.5)$ \\
\hline Female & $91(45.5)$ \\
\hline Age (yr) & $57.2 \pm 16.3$ \\
\hline Provisional diagnosis & \\
\hline Thyroid and parathyroid disease & $79(39.5)$ \\
\hline Cervical spine disease & $28(14)$ \\
\hline Oropharyngeal disease & $24(12)$ \\
\hline Nasopharyngeal disease & $21(10.5)$ \\
\hline Other diseases & $48(24)$ \\
\hline
\end{tabular}

${ }^{a}$ Other diseases: dental, larynx, facial bone, and sinus diseases. 
Table 2. Measurements of pedicle width, internal height and isthmus height of C2 vertebra from CCT scan and TPCT scan

\begin{tabular}{|c|c|c|c|c|c|c|c|c|c|c|c|c|}
\hline & \multicolumn{3}{|c|}{ Mean (mm) } & \multicolumn{3}{|c|}{$\operatorname{Min}(\mathrm{mm})$} & \multicolumn{3}{|c|}{$\operatorname{Max}(\mathrm{mm})$} & \multicolumn{3}{|c|}{$\mathrm{SD}(\mathrm{mm})$} \\
\hline & CCT & \multicolumn{2}{|c|}{ TPCT } & ССТ & \multicolumn{2}{|c|}{ TPCT } & СCT & \multicolumn{2}{|c|}{ TPCT } & ССТ & \multicolumn{2}{|c|}{ TPCT } \\
\hline Pedicle width & 5.07 & \multicolumn{2}{|c|}{4.87} & 1.1 & \multicolumn{2}{|c|}{1.1} & 9.31 & \multicolumn{2}{|c|}{9.11} & 1.31 & \multicolumn{2}{|c|}{1.27} \\
\hline Internal height & 5.61 & $5.27^{\mathrm{a})}$ & $4.51^{b)}$ & 1.17 & $1.17^{\mathrm{al}}$ & $0.87^{\text {b) }}$ & 15.24 & $12.1^{\mathrm{al}}$ & $11.59^{b)}$ & 2.3 & $1.61^{\text {a) }}$ & $2.16^{b)}$ \\
\hline Isthmus height & 10.18 & $10.28^{a)}$ & $9.72^{\mathrm{bl}}$ & 4.44 & $5.42^{\text {a) }}$ & $5.19^{b)}$ & 20.02 & $15.31^{\mathrm{a})}$ & $17.39^{b)}$ & 1.85 & $1.61^{\text {a) }}$ & $1.76^{\text {b) }}$ \\
\hline
\end{tabular}

CCT, conventional computed tomography; TPCT, thin-sliced pedicular oriented computed tomography; SD, standard deviation.

${ }^{a}$ Value of sagittal cut at $2 \mathrm{~mm}$ from lateral border of spinal canal; ${ }^{b / V a l u e ~ o f ~ s a g i t t a l ~ c u t ~ a t ~} 3 \mathrm{~mm}$ from lateral border of spinal canal.

Table 3. Prevalence of vertebral artery groove anomaly

\begin{tabular}{lccc} 
Type of VA groove anomaly & $\begin{array}{c}\text { Conventional CT scan } \\
\text { measurement }(\%)\end{array}$ & $\begin{array}{c}\text { Thin-sliced pedicular oriented } \\
\text { CT scan measurement }(\%)\end{array}$ & 22.83 \\
Narrow pedicles & 15.58 & 16.54 & $<0.001^{\text {b) }}$ \\
HRVA & 6.01 & $<.001^{\mathrm{b})}$ \\
\hline
\end{tabular}

VA, vertebral artery; CT, computed tomography; HRVA, high riding vertebral artery.

${ }^{\text {a) } M c N e m a r ' s ~ t e s t ;}{ }^{\text {b) }}$ Statistical significance $(p<0.05)$.

9.72 mm (range, 5.19-17.39 mm; SD, 1.76) (Table 2).

There were 23 high-riding vertebral arteries (6.01\%, $95 \%$ confidence interval $[\mathrm{CI}], 3.61 \%-8.39 \%)$ detected with CCT, whereas 66 high-riding vertebral arteries (16.54\%; 95\% CI, 12.85\%-20.23\%) were detected by TPCT $(p<0.001)$. There were 62 narrow pedicles $(15.58 \%$; 95\% CI, 11.99\%-19.15\%) detected with CCT, whereas 90 narrow pedicles (22.83\%; 95\% CI, 18.58\%-26.87\%) were detected with TPCT $(p<0.001)$ (Table 3$)$.

\section{Discussion}

Posterior atlantoaxial transarticular screw fixation and C2 pedicle screws are popular techniques used to stabilize and provide a high fusion rate for the atlantoaxial joint $[6,10,12]$; however, fatal complications, such as VA injury resulting from the misplacement of these screws have been reported [10]. The reported rate of VA injury due to posterior atlantoaxial transarticular screw fixation and C2 pedicular screw fixation was between $4.1 \%-8.2 \%$ and $5.3 \%-21 \%$, respectively $[3,4,8,9]$. Additionally, it has been reported that variations in the VAG morphology of C2 increases the risk of injury to the VA [20].

Several authors have recommended a preoperative CT scan to assess VAG anomalies; however, there is no widely accepted technique for this task. The CCT scan has limitations for evaluating VAG anomalies. A slice interval of 3 $\mathrm{mm}$ is not sufficiently accurate to reveal a VAG anomaly, as shown in many previous reports and can result in misleading the screw placement [7,12] (Fig. 2). Retro-reformation, although performed, is usually for the orthogonal planes and limits the evaluation of structures running in an oblique direction. Kim et al. [19] also reported that a CCT scan is not the gold standard to evaluate VAG.

Many techniques have been applied to evaluate the VAG and the size of the C2 pedicle. Dull and Toselli [21] recommended oblique axial CT imaging for preoperative planning of C1-2 transarticular screw fixation. Moreover, Wang et al. [12] used 1-mm slices on a CT scan with a pedicular-oriented plane and $15-20^{\circ}$ angle cephalad to evaluate VAG. In addition, Neo et al. [10] used a CT scan with a 1-mm slice interval to reconstruct sagittal and coronal images at 3-mm intervals to localize the VA. All studies used the most medial slice from the lateral edge of the spinal canal to evaluate HRVA, which is consistent with the findings of the present study. Some authors recommend using a computer-assisted navigation system to evaluate the VAG of C2, but it is a more complex method $[6,7,22]$. We conducted this study as a trial to identify a safe, simple, and cost-effective method to evaluate VAG of C2.

From the perspective of an anatomical study regarding the entry point and trajectory of both screw insertion techniques, cadaveric studies performed by Madawi et al. 

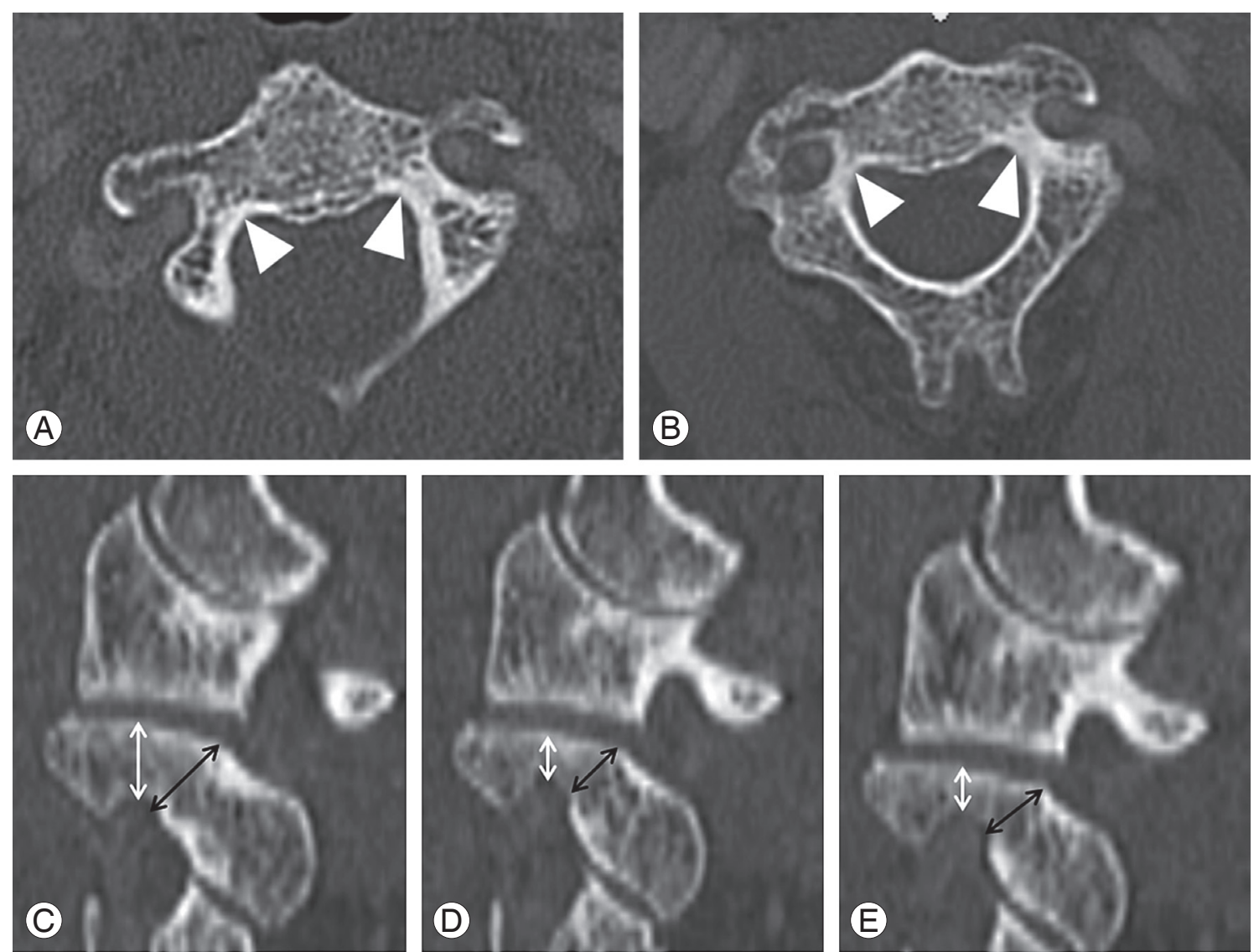

Fig. 2. An axial slice (A) of a conventional computed tomography (CT) scan obtained from a 40 -year-old male patient. The axial pedicular-oriented plane (B) of the same level demonstrates the full length of the pedicles bilaterally (arrowheads). Sagittal reformation of a conventional CT scan (C), thin-sliced sagittal reformation at $2 \mathrm{~mm}$ (D), and $3 \mathrm{~mm}$ (E) from the lateral border of the spinal canal. The measurement in panel (C) shows that the isthmus height of the C2 pedicle (black arrows) and internal height of lateral mass (white arrows) is incorrectly higher and thicker than in panels (D) and (E), which may result in a trajectory error.

[3] found that the mean width of the C2 pedicle was 7.8 $\mathrm{mm}$. The mean, median angle, superior angle, and facetpedicle angle were $32.4^{\circ}, 24.0^{\circ}$, and $14.2^{\circ}$, respectively [3]. Harms and Melcher [5] recommended that the entry point for a $\mathrm{C} 2$ pedicular screw should be the cranial and medial quadrant of the $\mathrm{C} 2$ isthmus surface and should be in the cephalad direction. Magerl and Seemann [23] suggested the entry point for the C1-2 transarticular screw to be $2-3 \mathrm{~mm}$ lateral to the lamina-lateral mass junction and $3 \mathrm{~mm}$ above $\mathrm{C} 2-3$ joint line; the trajectory was along the central axis of the $\mathrm{C} 2$ pedicle across the posterior edge of $\mathrm{C} 1-2$ facet joint into the lateral mass of $\mathrm{C} 1$. In addition, Alosh et al. [24] reported that during $\mathrm{C} 2$ pedicular screw placement, the likelihood of a cortical breach may be associated with the size of the pedicle shown on the presurgical thin-slice CT scan. We presumed that the screw should pass the $\mathrm{C} 2$ isthmus at $2-3 \mathrm{~mm}$ from the lateral wall of the spinal canal. This is in line with a previous study by Paramore et al. [13].

In this study, we found that a preoperative thin-sliced CT scan with a pedicular-oriented plane detected a significantly higher prevalence of VAG anomalies compared to CCT scans. This may be due to two reasons: (1) the scanning plane that was performed along the long axis of the pedicle can indicate the true length and width of the pedicle compared to the orthogonal plane of a CCT scan; and (2) the thinner the slice, the more detail it can provide. Therefore, a slice thickness of $\leq 3 \mathrm{~mm}$ improved the accuracy for assessing the pedicular screw position. In addition, the most recent CT machines can scan patients using a volumetric process and retro-reconstruction can be subsequently performed, in which the images can be reconstructed along any plane with a very thin slice (as thin as $0.6 \mathrm{~mm}$ ).

The prevalence of HRVA according to the TPCT measurements was $16.54 \%$, which was consistent with the 
Table 4. Previously published prevalence of HRVA and narrow pedicle of C2

\begin{tabular}{|c|c|c|c|c|c|}
\hline Study & $\begin{array}{c}\text { Publication } \\
\text { (yr) }\end{array}$ & $\begin{array}{l}\text { Characteristic } \\
\text { of the studies }\end{array}$ & $\begin{array}{l}\text { No. of study } \\
\text { population }\end{array}$ & HRVA (\%) & $\begin{array}{c}\text { Narrow pedicle } \\
\text { of C2 }(\%)\end{array}$ \\
\hline Present study & & $\begin{array}{l}\text { CT scan } \\
\text { (TPCT) }\end{array}$ & 200 & 16.5 & 22.8 \\
\hline Wakao et al. [18] & 2014 & 3D-CTA & 387 & 10.1 & NA \\
\hline Yeom et al. [7] & 2013 & CT scan & 261 & 14.5 & 9.5 \\
\hline Yamazaki et al. [17] & 2012 & 3D-CTA & 100 & 31 & NA \\
\hline Mandel et al. [11] & 2000 & Cadaveric study & 205 & 11.7 & NA \\
\hline Madawi et al. [3] & 1997 & Cadaveric study & 25 & 20 & 20 \\
\hline Paramore et al. [13] & 1996 & CT scan & 94 & 18 & NA \\
\hline
\end{tabular}

HRVA, high riding vertebral artery; CT, computed tomography; TPCT, thin-sliced pedicular oriented computed tomography scan measurement; 3DCTA, 3-dimensional computed tomographic angiography; NA, not data available.

previous cadaveric studies performed by Madawi et al. [3] and Mandel et al. [11] who demonstrated that the prevalence of HRVA ranged from $11.7 \%$ to $20 \%$ (Table 4). Using TPCT measurements, we were able to detect HRVA at a similar rate to other advanced imaging techniques, such as 3D-CTA studies, which range from $10.1 \%$ to $31 \%[7,13,17,18]$ (Table 4 ). Compared with 3D-CTA, TPCT measurements are easier to perform, safer, and can be used in patients with impaired renal function. Moreover, using CT angiography, the patients are exposed to a greater extent of radiation than with the TPCT measurement method, since both the plain and contrast-enhanced studies need to be conducted. In addition, there may be certain risks related to the use of contrast media, such as neurovascular injury and allergies, which can be potentially lethal. The prevalence of HRVA from the Yamazaki et al. [17] study was much higher than that reported in other imaging studies (including the present study), which may be due to subject selection bias. The majority of the subjects in that study underwent surgery due to an anomaly of the craniovertebral junction, so the higher rate of HRVA may be related to such anomalies.

Previous studies have reported that the prevalence of narrow pedicles ranged from $9.5 \%$ to $32 \%[7,12]$, which was in agreement with our study when using the thinsliced pedicular-oriented plane.

The limitations of this study include the fact that it is a cross-sectional imaging study, and not a clinical outcomebased study. Moftakhar et al. [25] suggested that despite screw perforation, VA injury rarely occurred because there is a relatively large space between the bone and artery. Therefore, the prevalence of VAG anomalies in this study does not reflect the incidence of VA injury in normal clinical practice. Another limitation is the retrospective nature of the study design. Based on our data, we were not able to identify an association between the HRVA and the parameters that we analyzed in this study. Furthermore, research to evaluate the CT findings of VAG, the prevalence of VA injury, and the clinical outcome will be of great benefit for patients undergoing surgery. Close collaboration between the spine surgeons and the musculoskeletal radiologists as a team will help to improve imaging accuracy.

\section{Conclusions}

VAG anomalies are commonly observed. Preoperative evaluation using TPCT reconstructed from an existing CCT revealed a significantly higher prevalence of C2 VAG anomalies compared to the CCT, and demonstrated comparable prevalence to the previously-published studies using more sophisticated and riskier techniques. Therefore, we propose TPCT as an alternative preoperative evaluation for the placement of C2 screws and trajectory planning.

\section{Conflict of Interest}

No potential conflict of interest relevant to this article was reported.

\section{Acknowledgments}

The authors would like to thank Dr. Panunan Sasiprapha 
for technical support. The authors wish to thank Mr. Dittapol Monthum and Mrs.Sasivimol Rattanasiri for statistical analysis assistance.

\section{References}

1. Goel A, Laheri V. Plate and screw fixation for atlantoaxial subluxation. Acta Neurochir (Wien) 1994;129: 47-53.

2. Peng CW, Chou BT, Bendo JA, Spivak JM. Vertebral artery injury in cervical spine surgery: anatomical considerations, management, and preventive measures. Spine J 2009;9:70-6.

3. Madawi AA, Casey AT, Solanki GA, Tuite G, Veres R, Crockard HA. Radiological and anatomical evaluation of the atlantoaxial transarticular screw fixation technique. J Neurosurg 1997;86:961-8.

4. Wright NM, Lauryssen C. Vertebral artery injury in C1-2 transarticular screw fixation: results of a survey of the AANS/CNS section on disorders of the spine and peripheral nerves. American Association of Neurological Surgeons/Congress of Neurological Surgeons. J Neurosurg 1998;88:634-40.

5. Harms J, Melcher RP. Posterior C1-C2 fusion with polyaxial screw and rod fixation. Spine (Phila $\mathrm{Pa}$ 1976) 2001;26:2467-71.

6. Yoshida M, Neo M, Fujibayashi S, Nakamura T. Comparison of the anatomical risk for vertebral artery injury associated with the C2-pedicle screw and atlantoaxial transarticular screw. Spine (Phila Pa 1976) 2006;31:E513-7.

7. Yeom JS, Buchowski JM, Kim HJ, Chang BS, Lee CK, Riew KD. Risk of vertebral artery injury: comparison between C1-C2 transarticular and C2 pedicle screws. Spine J 2013;13:775-85.

8. Yeom JS, Buchowski JM, Park KW, Chang BS, Lee $\mathrm{CK}$, Riew KD. Undetected vertebral artery groove and foramen violations during C1 lateral mass and C2 pedicle screw placement. Spine (Phila Pa 1976) 2008;33:E942-9.

9. Ondra SL, Marzouk S, Ganju A, Morrison T, Koski T. Safety and efficacy of C2 pedicle screws placed with anatomic and lateral C-arm guidance. Spine (Phila Pa 1976) 2006;31:E263-7.

10. Neo M, Matsushita M, Iwashita Y, Yasuda T, Sakamoto T, Nakamura T. Atlantoaxial transarticular screw fixation for a high-riding vertebral artery. Spine (Phila
Pa 1976) 2003;28:666-70.

11. Mandel IM, Kambach BJ, Petersilge CA, Johnstone B, Yoo JU. Morphologic considerations of C2 isthmus dimensions for the placement of transarticular screws. Spine (Phila Pa 1976) 2000;25:1542-7.

12. Wang J, Xia H, Ying Q, et al. An anatomic consideration of $\mathrm{C} 2$ vertebrae artery groove variation for individual screw implantation in axis. Eur Spine J 2013;22:1547-52.

13. Paramore CG, Dickman CA, Sonntag VK. The anatomical suitability of the C1-2 complex for transarticular screw fixation. J Neurosurg 1996;85:221-4.

14. Dickman CA, Sonntag VK. Posterior C1-C2 transarticular screw fixation for atlantoaxial arthrodesis. Neurosurgery 1998;43:275-80.

15. Bloch O, Holly LT, Park J, Obasi C, Kim K, Johnson JP. Effect of frameless stereotaxy on the accuracy of C1-2 transarticular screw placement. J Neurosurg 2001;95:74-9.

16. Jun BY. Anatomic study for ideal and safe posterior C1-C2 transarticular screw fixation. Spine (Phila Pa 1976) 1998;23:1703-7.

17. Yamazaki M, Okawa A, Furuya T, et al. Anomalous vertebral arteries in the extra- and intraosseous regions of the craniovertebral junction visualized by 3-dimensional computed tomographic angiography: analysis of 100 consecutive surgical cases and review of the literature. Spine (Phila Pa 1976) 2012; 37:E1389-97.

18. Wakao N, Takeuchi M, Nishimura M, et al. Vertebral artery variations and osseous anomaly at the C1-2 level diagnosed by 3D CT angiography in normal subjects. Neuroradiology 2014;56:843-9.

19. Kim HS, Heller JG, Hudgins PA, Fountain JA. The accuracy of computed tomography in assessing cervical pedicle screw placement. Spine (Phila Pa 1976) 2003;28:2441-6.

20. Abou Madawi A, Solanki G, Casey AT, Crockard HA. Variation of the groove in the axis vertebra for the vertebral artery. Implications for instrumentation. J Bone Joint Surg Br 1997;79:820-3.

21. Dull ST, Toselli RM. Preoperative oblique axial computed tomographic imaging for C1-C2 transarticular screw fixation: technical note. Neurosurgery 1995; 37:150-1.

22. Ebraheim N, Rollins JR Jr, Xu R, Jackson WT. Anatomic consideration of $\mathrm{C} 2$ pedicle screw placement. 
Spine (Phila Pa 1976) 1996;21:691-5.

23. Magerl F, Seemann PS. Stable posterior fusion of the atlas and axis by transarticular screw fixation. In: Kehr P, Weidner A, editors. Cervical spine. Wien: Springer-Verlag; 1986. p.322-7.

24. Alosh H, Parker SL, McGirt MJ, et al. Preoperative radiographic factors and surgeon experience are as- sociated with cortical breach of C2 pedicle screws. J Spinal Disord Tech 2010;23:9-14.

25. Moftakhar P, Gonzalez NR, Khoo LT, Holly LT. Osseous and vascular anatomical variations within the C1-C2 complex: a radiographical study using computed tomography angiography. Int J Med Robot 2008;4:158-64. 